\section{Review}

Correspondence

Susan M. Logan

susan.logan@nrc-cnrc.gc.ca

\title{
Flagellar glycosylation - a new component of the motility repertoire?
}

\author{
Susan M. Logan \\ Institute for Biological Sciences, National Research Council, Ottawa, Ontario K1A OR6, Canada
}

\begin{abstract}
The biosynthesis, assembly and regulation of the flagellar apparatus has been the subject of extensive studies over many decades, with considerable attention devoted to the peritrichous flagella of Escherichia coli and Salmonella enterica. The characterization of flagellar systems from many other bacterial species has revealed subtle yet distinct differences in composition, regulation and mode of assembly of this important subcellular structure. Glycosylation of the major structural protein, the flagellin, has been shown most recently to be an important component of numerous flagellar systems in both Archaea and Bacteria, playing either an integral role in assembly or for a number of bacterial pathogens a role in virulence. This review focuses on the structural diversity in flagellar glycosylation systems and demonstrates that as a consequence of the unique assembly processes, the type of glycosidic linkage found on archaeal and bacterial flagellins is distinctive.
\end{abstract}

\section{Introduction}

The bacterial flagellum, a key component of bacterial motility, is recognized as playing a vital role in the exquisite ability of many bacteria to adapt to the great diversity of biological niches in which they are found. This diversity includes aquatic and soil environments as well as the unique microenvironments which bacterial pathogens colonize within their respective protozoal, plant or animal host(s). While the model organisms for understanding the process of flagellar biosynthesis, assembly and regulation have been Salmonella enterica serovar Typhimurium strain LT2 and Escherichia coli K-12 (Aldridge \& Hughes, 2002; Macnab, 2003), both of which produce peritrichous flagella composed of a single flagellin structural protein (simple flagella), recent post-genomic analysis has indicated that this existing paradigm reflects in general terms a degree of structural and regulatory conservation across the bacterial phyla (Pallen et al., 2005). However, the definitive contribution of the flagellar organelle to numerous unique bacterial lifestyles remains to be established. It is possible that the wellestablished paradigm defined by the motility systems of these two organisms may not be adequately encompassing for flagellar/motility systems from many distantly related bacterial species or indeed for alternative structures (lateral, polar or periplasmic flagella) of more closely related organisms. A recent body of work has described the process of flagellar glycosylation in a diverse number of bacterial species and in some cases has demonstrated a role for this process in both flagellar assembly and biological function. While it may be premature to consider glycosylation as a component of the flagellar repertoire, the intent of this review is to provide a current update on the extent of flagellar glycosylation in both Bacteria and Archaea, and to demonstrate that for a number of motile organisms it does appear to play a significant role both in flagellar assembly and in interactions of organisms with their surroundings.

\section{Flagellar structures}

A variety of flagellar structures other than the peritrichous, simple flagella commonly found on enteric bacteria have been described and are the subject of a number of recent detailed reviews to which the reader is referred (Bardy et al., 2003; Charon \& Goldstein, 2002; McCarter, 2001, 2004). It is noteworthy that a significant number of the flagellin structural protein monomers which are part of these alternative flagellar structures have recently been shown to be glycosylated at multiple sites (Table 1). As thousands of copies of these proteins are present within an assembled filament the biological role of these novel glycan components should not be overlooked. A brief summary of each of these alternative structures is presented.

A diverse range of bacterial species when grown in liquid medium will produce flagella which are described as polar. Both simple, polar flagella (e.g. Legionella pneumophila, Pseudomonas aeruginosa) and complex (more than one flagellin protein monomer) polar flagella (e.g. Caulobacter crescentus) have been described and these are found as either a single filament (monotrichous) or in a bundle (multitrichous) at either one or both (bipolar) ends of the cell. In addition, some organisms produce flagella which are covered with an external layer, the sheath (e.g. Vibrio parahaemolyticus). This structure has been described as an extension of the outer membrane, although in some cases it has been shown to be unique in composition (Doig \& Trust, 1994; Fuerst, 1980; Geis et al., 1993; Hranitzky et al., 1980; 
Table 1. Flagellin glycoproteins

\begin{tabular}{|c|c|c|c|c|c|}
\hline Organism & Type of flagella & Glycan linkage & No. of sites & Glycan characterization & Reference \\
\hline \multicolumn{6}{|l|}{ Gram-negative } \\
\hline \multirow[t]{2}{*}{ Aeromonas caviae Sch3 } & Polar, monotrichous, complex & $\mathrm{ND}$ & ND & Periodate oxidation & Rabaan et al. 2001) \\
\hline & Laf, complex & $\mathrm{ND}$ & ND & Periodate oxidation & Gavin et al. (2002) \\
\hline \multirow[t]{2}{*}{ Aeromonas caviae UU 51} & Polar, monotrichous, complex & $\begin{array}{l}\text { O-Linkage } \\
\text { Ser/Thr }\end{array}$ & $\begin{array}{l}\text { FlaA } 6 \text { sites, } \\
\text { FlaB } 7 \text { sites }\end{array}$ & Pse5Ac7Ac8Ac & Schirm et al. (2005) \\
\hline & Laf, complex & $\mathrm{ND}$ & $\mathrm{ND}$ & $\mathrm{ND}$ & \\
\hline \multirow[t]{2}{*}{ Aeromonas hydrophila $\mathrm{AH} 3$} & Polar, monotrichous, complex & ND & ND & Periodate oxidation & Rabaan et al.(2001) \\
\hline & Laf, complex & ND & ND & Periodate oxidation & Gavin et al. (2002) \\
\hline Agrobacterium tumefaciens $\mathrm{C} 58 \mathrm{C} 1$ & Polar, monotrichous, complex & ND & ND & Periodate oxidation & Deakin et al. (1999) \\
\hline \multirow[t]{2}{*}{ Azospirillium brazilense $\mathrm{Sp} 7$} & Polar, monotrichous, complex & $\begin{array}{l}\text { O-Linkage } \\
\text { Ser/Thr }\end{array}$ & ND & $\beta$-Elimination, SDS-PAGE & Moens et al. (1995) \\
\hline & Laf & $\mathrm{ND}$ & ND & $\mathrm{ND}$ & \\
\hline Campylobacter jejuni 81-176 & Bipolar, monotrichous, complex & $\begin{array}{l}\text { O-Linkage } \\
\text { Ser/Thr }\end{array}$ & FlaA 19 sites & Pse5Ac7Ac, PseAm, Pse8OAc PseAmGlnAc & $\begin{array}{l}\text { Thibault et al. (2001); } \\
\text { Schirm et al. (2005) }\end{array}$ \\
\hline Campylobacter coli VC167 & Bipolar, monotrichous, complex & $\begin{array}{l}\text { O-Linkage } \\
\text { Ser/Thr }\end{array}$ & FlaA 16 sites & Pse5Ac7Ac, PseAm, Pse/PseAm-deoxypentose & Logan et al. (2002) \\
\hline Caulobacter crescentus CB15 & Polar, monotrichous, complex & $\mathrm{ND}$ & ND & Anomalous migration, SDS-PAGE & Johnson et al. (1983) \\
\hline Helicobacter pylori 1061 & $\begin{array}{l}\text { Polar, multitrichous, complex, } \\
\text { sheathed }\end{array}$ & $\begin{array}{l}\text { O-Linkage } \\
\text { Ser/Thr }\end{array}$ & $\begin{array}{l}\text { FlaA } 7 \text { sites, } \\
\text { FlaB } 10 \text { sites }\end{array}$ & Pse5Ac7Ac & Schirm et al. (2003) \\
\hline Helicobacter pylori NCTC 11637 & $\begin{array}{l}\text { Polar, multitrichous, complex, } \\
\text { sheathed }\end{array}$ & $\begin{array}{l}\text { O-Linkage } \\
\text { Ser/Thr }\end{array}$ & $\begin{array}{l}\text { FlaA } 7 \text { sites, } \\
\text { FlaB } 10 \text { sites }\end{array}$ & Pse5Ac7Ac & Schirm et al. (2005) \\
\hline Helicobacter felis CS1 & $\begin{array}{l}\text { Bipolar, multitrichous, complex, } \\
\text { sheathed }\end{array}$ & $\mathrm{ND}$ & $\mathrm{ND}$ & Anomalous migration SDS-PAGE & Josenhans et al. (1999) \\
\hline Pseudomonas aeruginosa PAK & Polar, monotrichous, simple & $\begin{array}{l}\text { O-Linkage } \\
\text { Ser/Thr }\end{array}$ & FliC 2 sites & $\begin{array}{l}\text { Rhamnose linking monosaccharide, } \\
\text { heterogeneous glycan with novel, } \\
\text { conserved trisaccharide capping }\end{array}$ & Schirm et al. (2004a) \\
\hline Pseudomonas aeruginosa $\mathrm{JJ692}$ & Polar, monotrichous, simple & $\begin{array}{l}\text { O-Linkage } \\
\text { Ser/Thr }\end{array}$ & FliC 2 sites & Rhamnose & Schirm et al. (2004a) \\
\hline Pseudomonas syringae & Polar, monotrichous, simple & ND & ND & $\begin{array}{l}\text { Trifluoromethanesulphonic acid (TFMS) } \\
\text { deglycosylation }\end{array}$ & $\begin{array}{l}\text { Takeuchi et al. (2003); } \\
\text { Taguchi et al. (2003) }\end{array}$ \\
\hline Borrelia burgdorferi & Periplasmic, complex & $\begin{array}{l}N \text {-Glycosidase } \\
\text { F sensitive } \\
\text { (FlaA) }\end{array}$ & ND & SNA, GNA lectin binding & Ge et al. (1998) \\
\hline Serpulina hyodysenteriae & Periplasmic, complex & $\begin{array}{l}N \text {-Glycosidase } \\
\text { F sensitive }\end{array}$ & ND & $\beta$-Elimination, SDS-PAGE & Li et al. (1993) \\
\hline Spirochaeta aurantia & Periplasmic, complex & $\mathrm{ND}$ & ND & Concanavalin A lectin binding & $\begin{array}{l}\text { Brahamsha \& Greenberg } \\
\text { (1988) }\end{array}$ \\
\hline Treponema pallidum & Periplasmic, complex & ND (FlaB) & ND & Periodate oxidation & Wyss (1998) \\
\hline
\end{tabular}




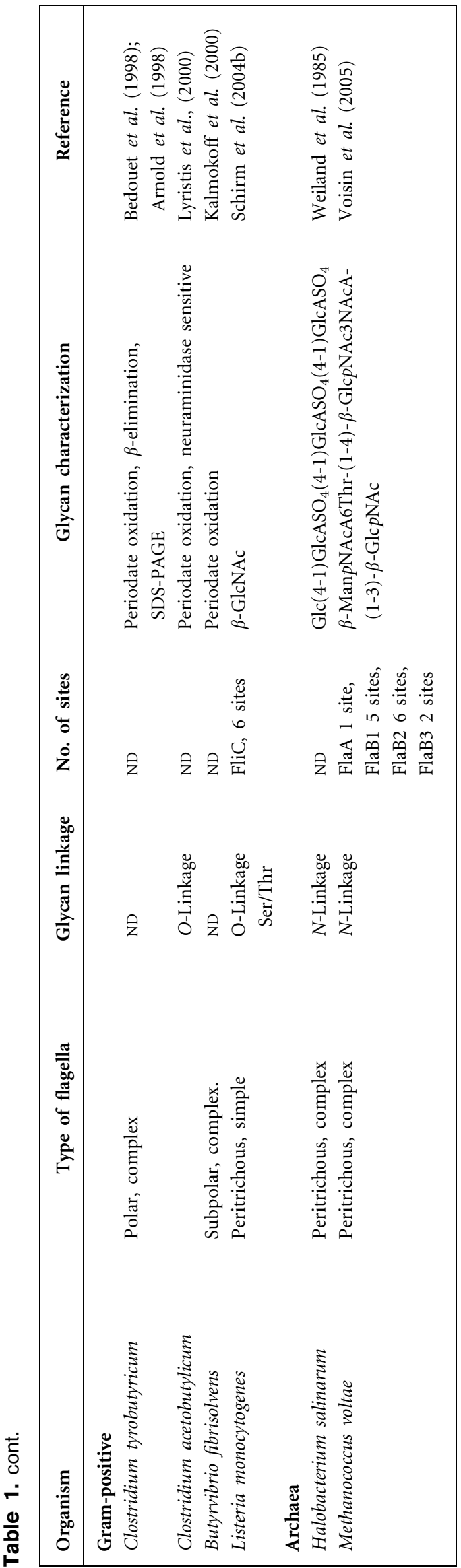

Thomashow \& Rittenberg, 1985a). Electron microscopy studies of a number of organisms with polar flagella have identified, in addition, a unique basal body structure which appears to be a convex disk situated below the outer membrane (Engelhardt et al., 1993; Ferris et al., 1984; Thomashow \& Rittenberg, 1985b). It remains to be established if this is an integral component of all polar structures and what role it contributes to the functioning of the polar flagellum.

As with the peritrichous flagella of enteric bacteria, lateral flagella (laf) are visible as a number of filaments extending at random points on the cell but not from either of the cell poles. Laf are in most cases composed of more than one flagellin structural protein and are induced when cells are grown on solid surfaces, where they have been shown to facilitate swarming. In most cases, organisms which produce these distinct peritrichous flagella are also capable of producing polar flagella when grown in broth.

In distinct contrast to these surface-expressed motility systems, the motility of spirochaetes is mediated by unique periplasmic flagella (Charon \& Goldstein, 2002). These flagellar organelles are attached subterminally to each end of the cell cylinder and the flagella function by rotating within the periplasmic space. A number of features distinguish these periplasmic flagella from the flagella of enteric bacteria, most notably the lack of $\mathrm{L}$ and $\mathrm{P}$ rings in the basal body as well as the composition of the flagellar filament. The filament is of the complex type, composed of a family of FlaB core proteins, and may be enveloped by a structure described as a sheath which is composed of only a single FlaA structural protein. The FlaB core proteins share N- and C-terminal homology with other bacterial flagellins while the FlaA protein bears no sequence similarity. FlaA is likely secreted to the periplasmic space by the Sec secretory pathway while FlaB secretion occurs through the basal body of the flagellar type III secretory apparatus (Brahamsha \& Greenberg, 1988; Li et al., 2000).

Finally, while flagellar-based motility is also a common feature of the Archaea, the structure produced in this kingdom is unique and more closely resembles type IV bacterial pili in its structure and mode of assembly (Bardy et al., 2004). The flagellar filament is generally complex in nature and composed of multiple flagellin structural proteins. Unlike bacterial flagellins, archaeal flagellin is expressed as a preflagellin protein with a leader peptide sequence which is cleaved by a signal peptidase to produce mature flagellin. This mature protein is secreted from the cell and incorporated at the base of the filament, a process which is in distinct contrast to the bacterial system, where flagellin is incorporated at the distal end of the growing filament.

\section{Glycoprotein structural analysis}

As a consequence of methodological advances in glycoprotein characterization (Dell \& Morris, 2001), considerable progress has been made in the structural characterization of flagellar glycans, most notably those from polar flagella of 
numerous Gram-negative bacteria. Mass spectrometry plays an integral part in the analysis of any novel glycoprotein, yet in the case of prokaryotic glycoproteins the presence of novel monosaccharides often in limited quantities presents unique challenges for structural analysis. However, with the increased sensitivity of mass spectrometers and recent advances in NMR technology, it is now possible to obtain detailed structural characterization from nanomolar amounts of purified glycan (Voisin et al., 2005). Initial analysis of a putative flagellar glycoprotein is the determination of the intact mass by either MALDI-TOF MS or ESI-MS. This provides preliminary information on the degree of glycosylation when prior sequence information is available. Recently, a 'top-down' approach has been used to provide more information on the novel $O$-linked glycans found on bacterial flagellins (Schirm et al., 2005). In brief, the labile nature of the glycosidic bond favours cleavage of $O$-linked glycans from glycoproteins when they are subjected to low-collision activation. Structural information is obtained on individual carbohydrate residues using a second-generation product ion scan of oxonium ions formed from this collisional activation of the intact protein ions. As an initial screening tool to establish the glycosylation status of novel proteins this approach requires minimal sample preparation and takes a relatively short time. More sophisticated 'top-down' approaches are possible using high-end mass spectrometry instruments, such as Fourier-transform ion cyclotron resonance mass spectrometry (FT-MS).

However, to precisely assign the type and location of the post-translational modifications a 'bottom-up' approach is most commonly utilized (Wysocki et al., 2005). This involves proteolytic cleavage of the original glycoprotein and separation of the corresponding products by liquid chromatography coupled to mass spectrometry (LC-MS) or capillary electrophoresis-nanoelectrospray mass spectrometry (CE-MS). The majority of the peptides will be readily identified based on mass alone at this stage; however, those that are not will then be examined by tandem mass spectroscopy (MS-MS). Glycopeptides display unique fragmentation patterns due to the labile nature of glycosidic bonds, and MS-MS spectra are typically dominated by fragment ions specific to the respective glycan. Accurate mass measurements of glycan oxonium ions provide plausible empirical formulae. To determine the glycan linkage site, either $\beta$-elimination experiments (for $O$-linked glycans) (Rademaker \& Thomas-Oates, 1996), where base-catalysed hydrolysis results in the incorporation of a newly formed amino group of distinct mass at the linkage site, or $\mathrm{MS}^{\mathrm{n}}$ on individual glycopeptides (for $\mathrm{N}$-linked glycans) can be performed. NMR has proven to be the most powerful technique for the definitive structural assignment of the novel prokaryotic glycans identified to date.

\section{Flagellar glycosylation}

Archaea. The glycosylation of archaeal flagellin is extensive throughout the kingdom although in the majority of examples only presumptive evidence based on glycoprotein-specific staining of the purified flagellin proteins is currently available. The exceptions are the flagellins of Halobacter salinarum and Methanococcus voltae. The first structural characterization of a flagellar glycan was provided by Wieland et al. (1985) for the flagellin of $H$. salinarum. The flagellin proteins were shown to be glycosylated in identical fashion to that of the cell surface S-layer proteins, with sulphated glucuronic acids through $\mathrm{N}$-glycosidic linkage. More recently, a complete structural characterization of flagellin proteins from $M$. voltae has revealed the presence of a novel trisaccharide of mass $779 \mathrm{Da}$ attached at each $\mathrm{N}$-linked sequon (Asn-X-Ser/ Thr) of the four flagellin structural proteins (Voisin et al., 2005). The structure of this novel glycan was determined by NMR and shown to be a trisaccharide composed of $\beta$ ManpNAcA6Thr-(1-4)- $\beta$-GlcpNAc3NAcA-(1-3)- $\beta$-GlcpNAc linked to Asn. As was the case for H. salinarum, the same trisaccharide was shown to be decorating the S-layer protein of M. voltae, implicating a common $N$-linked glycosylation pathway for these two major surface protein structures in the Archaea. The genetic basis for these processes remains ill defined at present.

\section{Gram-negative bacteria}

In addition to the numerous examples of motile organisms in aquatic environments, the gastrointestinal tract of humans and animals is host to both bacterial pathogens and natural flora, many of which require motility for effective colonization. Within this unique biological niche, a number of examples of flagellin glycosylation have recently become apparent. The genetics of flagellar glycosylation systems was recently included in a review of protein glycosylation in Gram-negative bacteria (Power \& Jennings, 2003).

Campylobacter spp. Probably the best-characterized polar flagellar glycosylation system is that of Campylobacter jejuni, a human gastrointestinal pathogen which produces bipolar flagella composed of two structural proteins FlaA and FlaB and which has recently been the subject of numerous reviews (Szymanski et al., 2003; Szymanski \& Wren, 2005). Motility of Campylobacter is essential for colonization of the viscous intestinal mucus in the human host (Black et al., 1988) and the flagellin protein is the immunodominant antigen on the cell surface. While the post-translational modification of Campylobacter flagellin had been described by Logan et al. (1989), and Alm et al. (1992) demonstrated variability in the mass of FlaA protein in different Campylobacter host backgrounds suggestive of variability in modifications amongst strains, it only became apparent that the protein was modified through glycosylation after the demonstration of sensitivity of the flagellin protein to periodic acid and a capacity to bind a sialic-acid-specific lectin (Doig et al., 1996). The definitive structural characterization of the FlaA protein was provided by Thibault et al. (2001). Campylobacter flagellins are the most heavily glycosylated flagellins characterized to date, with up to 19 sites in each FlaA monomer decorated in O-linkage at 
serine or threonine residues with the novel 'sialic acid like' monosaccharide 5,7-diacetamido-3,5,7,9-tetradeoxy-L-glycero-L-manno-nonulosonic acid (pseudaminic acid, Pse) and its acetamidino derivative (PseAm) along with minor quantities of a number of related derivatives made by individual strains (Logan et al., 2002; Schirm et al., 2005; Thibault et al., 2001). The FlaB protein is glycosylated in a similar fashion (unpublished observation). The sites of modification are localized to the central region of the primary sequence which, based on the crystal structure of flagellin from $S$. enterica, is predicted to be surface exposed in the assembled filament (Samatey et al., 2000).

Extensive genetic characterization (Goon et al., 2003; Guerry et al., 1996; Linton et al., 2000; Logan et al., 2002; Thibault et al., 2001) and the determination of the genome sequence of C. jejuni 11168 (Parkhill et al., 2000) has revealed a genetic locus of approximately 50 genes, including the $f l a A$ and $f l a B$ structural genes, which is responsible for this glycosylation. Campylobacter isolates display significant genetic diversity within this locus, which has been shown to be responsible for the antigenically distinct PseAm glycan variants produced by individual strains (Logan et al., 2002). Most recently, comparative phylogenomics revealed a cluster of six genes within this locus to be a specific marker for a 'livestock' clade (Champion et al., 2005), although the role of these genes in production of a unique glycoform relevant to adhesion in the livestock gut has yet to be demonstrated. The annotation of the locus suggested that approximately $50 \%$ of the genes were likely to be involved in carbohydrate biosynthetic pathways and that some of them had homology to sialic acid biosynthesis genes (neuA, neuB, neuC). Several studies, including structural investigations of flagellin from isogenic mutants (Creuzenet, 2004; Goon et al., 2003; Logan et al., 2002; Obhi \& Creuzenet, 2005; Thibault et al., 2001) and a novel metabolomic analysis (Soo et al., 2004), have provided proof that a number of these biosynthetic genes are indeed involved in the biosynthetic pathway of either Pse or PseAm. It is significant that while the function of the key enzymes PseB, PseC and NeuB in the biosynthetic pathway of Pse have recently been elucidated in detail (Chou et al., 2005; Schoenhofen et al., 2006) the identification and characterization of the glycosyltransferase(s) responsible for the addition of these novel monosaccharides to the flagellin protein remains elusive. No obvious candidate gene is apparent in the flagellar glycosylation locus although the homologue of $f l m D$ (Cj1312) from the Caulobacter crescentus flagellar glycosylation locus (see below) may be a potential candidate.

A unique feature of the glycosylation locus is the presence of multiple copies of hypothetical genes encoding proteins belonging to the motility accessory family (Maf) of flagellinassociated proteins, which have homologues in only a limited number of bacterial species, including Helicobacter, Wolinella and Clostridium spp. There are seven members of these genes in the C. jejuni 11168 locus, yet, while several Maf members have been shown to be involved in motility
(Karlyshev et al., 2002), the specific role of these proteins in the glycosylation process is currently unknown. A second paralogous gene family, the 617 family, includes four members in the glycosylation locus of C. jejuni 11168 (Cj1305, Cj1306, Cj1310 and Cj1342). As with the Maf family of proteins, slipped-strand mispairing appears to lead to phasevariable gene expression. To date no homologues of the 617 family have been found in other bacterial species.

In contrast to the assembly process of peritrichous flagella of the enteric bacteria, the glycosylation of Campylobacter flagellin is essential for flagellar assembly and consequent motility. Mutants in Pse biosynthetic genes in several strains of Campylobacter are non-motile and accumulate intracellularly flagellin of reduced molecular mass (Goon et al., 2003). Analysis of the flagellin by mass spectroscopy confirmed the lack of any glycosylation, providing specific proof of a functional role for the glycosylation process in flagellar assembly. Significantly, one of the key Pse biosynthetic genes, $p s e B$, is under the control of a $\sigma^{54}$ promoter (Goon et al., 2003) which is well recognized as the late-stage regulator within the flagellar regulon, and a number of other flagellin glycosylation genes have been shown by bioinformatics analysis to lie downstream of $\sigma^{28}$-dependent promoter sequences (Carrillo et al., 2004). This coregulation of flagellar glycosylation genes by the two key transcriptional regulators for the flagellar regulon emphasizes the integral role played by this process in the assembly of a functional filament.

Helicobacter spp. In contrast to Campylobacter, the complex flagella of Helicobacter spp. are assembled at one or both poles of the cell as either a single flagellum or a bundle of filaments, which in some cases are enveloped in an external sheath (Fox, 2002). In Helicobacter pylori, the human gastric pathogen, the flagellar filament is unique in appearance due to the presence of a terminal bulb at the distal end of each filament. Members of the genus have been isolated from the stomachs, intestines and caeca of humans and numerous animal species. Motility is essential for colonization of these diverse mucosal surfaces (Eaton et al., 1996; Andrutis et al., 1997). The first evidence that the flagellin of this genus was glycosylated was provided by Josenhans et al. (1999) in studies on Helicobacter felis. Subsequent studies (Josenhans et al., 2002) demonstrated glycosylation of flagellin from $H$. pylori and in addition identified two genes HP0326a and HP0326b, homologues of the Campylobacter flagellar glycosylation genes Cj1311 (neuA) and Cj1312 (flmD), which appeared to be involved in the glycosylation process. The detailed structural characterization of $H$. pylori flagellin revealed that both the FlaA and FlaB structural proteins were glycosylated in H. pylori (Schirm et al., 2003, 2005) in a similar manner to $C$. jejuni, with Pse found at seven sites on the FlaA protein and ten sites on the FlaB protein. A significant difference in the modification profile is the lack of heterogeneity in the composition of glycans found on $H$. pylori flagellin. It is possible that the presence of 
the flagellar sheath in this organism may indeed reduce the need for Helicobacter cells to invest significant resources in the production of a number of diverse, novel glycosylated structures. Correspondingly, in contrast to Campylobacter, bioinformatics studies have indicated a far simpler glycosylation gene content, and the functional characterization of a number of these genes has defined their roles in the Pse biosynthetic pathway. The biosynthetic genes HP0840, HP0178, HP0326A and HP0326B and HP0366 have received considerable attention (Creuzenet et al., 2000; Merkx-Jacques et al., 2004; Schirm et al., 2003; Schoenhofen et al., 2006) and their role in the biosynthesis of Pse is now clearly established. The genome sequences of $H$. pylori revealed the presence of only two Maf family homologues, HP0114 and HP0465 (Alm et al., 1999; Tomb et al., 1997). Significantly, while insertional inactivation of only HP0114 resulted in loss of motility, a novel metabolomic analysis of an isogenic HP0114 mutant revealed no effect on the production of CMP-Pse in the cytosol of the cell (Schirm et al., 2003). This is the first proof that while the Maf family of proteins clearly play a role in flagellar assembly they are not involved in the biosynthetic pathway of Pse.

Wolinella succinogenes. This is a Gram-negative commensal bacterium isolated from the bovine rumen and is a close relative of Campylobacter and Helicobacter. The flagellar structure of this polar-flagellated organism has received considerable attention due to its distinctive flagellar motor (for a review see Schuster \& Khan, 1994). While no structural studies have been completed to date on the flagellin protein, bioinformatic examination of the $W$. succinogenes genome indicates that, as in Helicobacter and Campylobacter spp., it is likely that the structural proteins will also be glycosylated. The precise structure of the glycan found on these flagellin proteins may provide insight into the unique rumen niche in which the organism is found.

Aeromonas spp. Aeromonads are ubiquitous aquatic bacteria which can cause disease in fish, amphibians and reptiles. In addition, the mesophilic aeromonad species are significant human pathogens causing, most commonly, gastrointestinal infections but have also been associated with wound disease and septicaemia (Thornley et al., 1997). Aeromonads are very efficient colonizers of surfaces and have been long recognized as key members of bacterial biofilms in both water distribution systems and foodprocessing environments. As with $V$. parahaemolyticus, two types of flagella have been shown to be responsible for motility. A polar unsheathed flagellum is expressed in broth culture or liquid environments (Rabaan et al., 2001), whereas the production of lateral flagella (laf) can be induced upon contact with solid surfaces or in the laboratory when the bacteria are grown on solid media (Kirov et al., 2002). Characterization of flagellar glycosylation systems has focused on the mesophilic aeromonads Aeromonas hydrophila and Aeromonas caviae. Polar flagella of both these species are complex, being composed of two structural proteins, FlaA and FlaB, and were shown by Rabaan et al. (2001) to be glycosylated based on periodate oxidation and reaction with biotin hydrazide. 'Top-down' mass spectrometry on purified flagellin has recently identified that up to six sites on FlaA and seven sites on the FlaB monomer are glycosylated with a derivative of Pse in O-linkage of mass $373 \mathrm{Da}$ (Schirm et al., 2005). At the genetic level, a flagellar glycosylation operon was identified in A. caviae through a transposon mutagenesis study in which bacterial adherence was decreased. Insertional inactivation of three of the five genes in this operon resulted in loss of motility, and polar flagellin was no longer detected by immunoblotting in cell lysates, providing clear evidence for an integral role of glycosylation in filament assembly (Gryllos et al., 2001). As the structural analysis revealed that the protein was glycosylated with a derivative of Pse, it is not surprising that the genes in this locus show significant homology to the Pse biosynthetic genes of $C$. jejuni and $H$. pylori, namely pseB, pseC, neuA and $n e u B$, as well as the flagellar glycosylation gene $f \operatorname{lm} D$ from C. jejuni, H. pylori and Caulobacter crescentus, for which no precise function has been described. Laf of Aeromonas appear also to be complex in composition and again preliminary evidence has been presented indicating that the structural proteins may be glycosylated (Gavin et al., 2002). It remains to be established if the glycan(s) decorating the lateral flagellins are identical to that found on polar flagella.

It is noteworthy that no evidence for glycosylation of either flagellin species in $V$. parahaemolyticus, another major gastrointestinal pathogen which produces both a sheathed polar flagellum as well as lateral flagella, has been reported (McCarter, 2004).

Caulobacter crescentus. The unique developmental lifestyle of this aquatic bacterium, which includes the production of a unipolar, unsheathed, complex flagellar filament in only swarmer cell progeny, has resulted in a comprehensive analysis of the process of flagellum biogenesis in this organism (Gober \& Marques, 1995). While the first description of a putative bacterial flagellar glycosylation locus can be attributed to C. crescentus and was presented by Leclerc et al. (1998) following earlier work in which the identification of a number of genes which affected flagellar assembly was made (Johnson et al., 1983), no definitive evidence for glycosylation of the flagellin proteins has yet to be presented. Orthologues of several of the genes identified in these studies which are present in a number of other bacterial species have since been shown to be involved in biosynthesis of flagellar glycans (FlmA, FlmB, FlmC, FlmD and FlmH). The polar filament of C. crescentus has been shown to be composed of three distinct structural proteins of molecular mass 29,27 and $25 \mathrm{kDa}$ (Driks et al., 1989); strains containing mutations in the putative glycosylation genes fail to assemble a flagellar filament and in some cases produce flagellins intracellularly 
of reduced molecular mass. The three $f \operatorname{lm}$ operons $f \operatorname{lm} A B$, flmEF and $f l m G H$ were shown to be regulated by CtrA, the transcriptional regulator which controls class II flagellar genes and as a consequence this novel group of genes was proposed to belong to a new class of flagellar genes in the C. crescentus flagellar regulon. No structural characterization of the flagellin proteins from $C$. crescentus has been completed to date, but the recent report of a role for flagella in initial attachment of these organisms to surfaces (Bodenmiller et al., 2004) raises the possibility that the glycan structure may indeed reveal important information on the mechanistic basis of this process.

Pseudomonas spp. In addition to being ubiquitous environmental organisms, a number of Pseudomonas species are opportunistic pathogens of both humans and plants, and motility appears to be critical to these processes. Motility is conferred on cells by either a single unsheathed polar flagellum or multitrichous polar flagella which are composed of a single flagellin structural protein, FliC. The flagellin proteins of the human pathogen $P$. aeruginosa can be classified as either a-type or b-type based on their molecular mass and reactivity with polyclonal antisera. Anomalous migration on SDS-PAGE was the first indication that the a-type flagellins were glycosylated (Totten \& Lory, 1990) and subsequent studies have revealed the structural nature of the glycan found on these flagellin proteins and the type of glycosidic linkage (Schirm et al., 2004a). The structural characterization of PAK flagellin revealed a heterogeneous glycan comprising up to 11 monosaccharide units in $\mathrm{O}$-glycosidic linkage which was attached through a rhamnose residue to the protein backbone at only two sites in the central, surface-exposed region of the protein monomer. In contrast to a second important cell-surface glycoprotein of $P$. aeruginosa, the pilin structural protein, which has been shown to be glycosylated with the $\mathrm{O}$ antigen repeat unit (Castric et al., 2001), the glycan decorating flagellin is unique in composition. This heterogeneous oligosaccharide was composed of pentose, hexose, hexuronic acid and deoxyhexose residues and was capped by a trisaccharide consisting of an aminodeoxyhexose, deoxyhexose and an unknown modification of molecular mass $174 \mathrm{Da}$. In a second a-type strain of $P$. aeruginosa, JJ692, the flagellin protein was glycosylated with a single rhamnose residue in $\mathrm{O}$-linkage at two sites (Schirm et al., 2004a).

Mutagenesis studies of the PAK flagellar glycosylation island indicated that the addition of rhamnose to the flagellin protein appears to be a process independent of that for addition of the heterogeneous glycan. Glycosylation of $P$. aeruginosa flagellin appears to have evolved into a two-stage process whereby initial glycosylation with a single rhamnose monosaccharide occurs and is likely common to all a-type strains. Additionally, the rhamnose moiety can be further modified through sequential extension, as was shown in the case of PAK, with a heterogeneous glycan capped with a conserved trisaccharide. In contrast to other species, where flagellar filament assembly is inhibited when the glycosylation process is interrupted, lack of glycosylation through mutation of the rhamnose-specific glycosyltransferase gene orf $N$ from the flagellar glycosylation island had no effect on flagellar assembly or subsequent motility in $P$. aeruginosa.

Genetic studies have revealed considerable polymorphism in the glycosylation islands of a-type strains (Arora et al., 2004), indicative of considerable diversity in the composition of the respective flagellar glycans. The identification of a glycosylation island containing four genes, two of which display homology to genes within the PAK glycosylation island, from the genome of strain $\mathrm{PAO}$, suggests that the flagellin from b-type strains may also be glycosylated.

In addition to the extensive structural characterization of flagellin it appears that glycosylation is important to virulence. In the burned mouse model of infection, genetically defined mutants which lacked flagellar glycosylation but still produced functional flagella were significantly attenuated in virulence (Arora et al., 2005).

The flagellins of the phytopathogenic bacteria Pseudomonas syringae pv. glycinea and pv. tomato have been shown to elicit hypersensitive cell death in non-host plants and recent work has clearly indicated that glycosylation of flagellin plays an integral role in this process and in host cell recognition. Genetic characterization of a putative glycosylation island of $P$. syringae pv. glycinea revealed a key role for the process in virulence (Taguchi et al., 2003; Takeuchi et al., 2003). As with P. aeruginosa, glycosylation was not required for flagellar assembly. The structure of the glycan on respective strains remains to be elucidated but it is anticipated that it will be significant in understanding the specificity of pathovars for respective plant species.

Azospirillum brasilense. This organism is a nitrogenfixing soil bacterium which colonizes plant roots and which like Vibrio and Aeromonas spp. is motile either by a single polar flagellum when grown in broth or, when grown on solid media, by laf. It has been shown that the polar flagellum is involved in adsorption of the organism to wheat roots (Croes et al., 2004). Preliminary evidence has also indicated that the structural protein is glycosylated through $O$-linkage, although the specific structure and degree of glycosylation on each monomer remains unknown (Moens et al., 1995).

Agrobacterium tumefaciens. Motility and chemotaxis have been long recognized as an important part of the ability of this well-studied plant pathogen to colonize the rhizosphere. Unlike enteric bacteria, but common to a number of rhizosphere-associated bacteria (e.g. Sinorhizobium meliloti) the flagellar structure and regulatory processes display a number of unique features (Krupski et al., 1985). The structure of the flagellar filament is complex and rotation of the polar flagella appears to be unidirectional. 
Four flagellin structural proteins (FlaA, FlaB, FlaC and FlaD) have been identified within a flagellar locus and examination of the proteins by SDS-PAGE indicated an anomalous mass for the FlaA protein. Glycan staining of the gel revealed that this protein was glycosylated (Deakin et al., 1999). The structural basis of glycosylation and its biological role in colonization of the rhizosphere for both $A$. tumefaciens and related organisms remains to be established.

Spirochaete periplasmic flagellins. Preliminary evidence indicates that both FlaA (sheath protein) and FlaB (filament proteins) of the flagellins from a number of spirochaete species are glycosylated. Early work by Brahamsha \& Greenberg (1988) utilizing lectin binding indicated that two of the three FlaB proteins of Spirochaeta aurantia were glycosylated based on reactivity with the lectin concanavalin A. Both FlaA and multiple FlaB flagellins of Serpulina hyodysenteriae (Li et al., 1993) were also shown to be glycosylated based on labelling studies and deglycosylation reactions. More recently, the structural FlaB flagellins of Treponema pallidum (Wyss, 1998) as well as the FlaA sheath protein of Borrelia burgdorferi (Ge et al., 1998) were shown to be glycosylated. While no detailed structural analysis of any spirochaete flagellin glycan has been completed, the reaction of B. burgdorferi FlaA protein with the lectins SNA (recognizes $\alpha(2-6)$ linked sialic acid residues) and GNA (recognizes terminal mannose) is indicative of a novel complex glycan structure. In addition, the sensitivity of this flagellar glycan to $\mathrm{N}$-glycosidase F suggests that, as with the archaeal flagellar glycans, the glycans of the FlaA protein may be present in $\mathrm{N}$-glycosidic linkage (Ge et al., 1998). However, bioinformatic analysis of the six spirochaete genomes currently available at NCBI revealed no evidence of a conserved STT3 ( $p g l B)$ oligosaccharyltransferase gene in any of these genomes. This protein is required for transfer of $N$-linked glycans from the lipid carrier to asparagine of the protein (for a review see Szymanski \& Wren, 2005). The precise chemical structure and type of glycosidic linkage found on both the FlaA sheath protein and individual FlaB filament proteins requires more extensive characterization as well as investigation into the role of this process in periplasmic flagellar assembly.

In summary, while there is currently no evidence for glycosylation of flagellins from the Enterobacteriaceae, polar flagella from a diverse range of other Gram-negative bacterial subdivisions appear to be glycosylated in O-linkage to serine/threonine residues. In bacteria which produce complex polar flagella (Campylobacter, Helicobacter, Aeromonas and Caulobacter), the process of glycosylation appears to be essential to the assembly process. In contrast, the glycosylation of the simple, polar flagella of Pseudomonas spp. is not essential to the assembly process. It remains to be established what type of glycosidic linkage is found on spirochaete flagellins and if this process is an integral part of the periplasmic flagellar assembly process.

\section{Gram-positive bacteria}

In comparison to Gram-negative bacteria, only three Grampositive bacterial genera have been shown to produce glycosylated flagellin. In contrast, the glycosylation of Slayer proteins has been extensively documented (Schaffer \& Messner, 2004).

Listeria monocytogenes. This Gram-positive bacterium responsible for listerioisis can survive in numerous adverse environments including high salts, and $\mathrm{pH}$ and temperature extremes. The organism produces four to six simple peritrichous flagella when grown at $<30{ }^{\circ} \mathrm{C}$. Initial observations on SDS-PAGE of the flagellin protein indicated discrepancy in mass from that predicted (Dons et al., 1992; Peel et al., 1988) and prompted the structural characterization of purified flagellin protein (Schirm et al., 2004b). In distinct contrast to the previous examples, where either novel monosaccharides or complex glycans were shown to be attached to the flagellin protein, the flagellin of L. monocytogenes is glycosylated at up to six sites per monomer, which are localized to the central region of the protein, with $\beta$-O-linked GlcNAc. The addition of GlcNAc would not require a novel glycan biosynthetic pathway, as GlcNAc is a common biosynthetic precursor of many pathways, but the requirement for an O-GlcNAc transferase enzyme is of significance. No homologue of the well-characterized eukaryotic enzyme is present in the genome of L. monocytogenes strains although a candidate glycosyltransferase gene (Lmo0688) can be found close to the flagellin structural gene, fliC. It remains to be established if glycosylation is required for flagellar assembly in this organism. While motility is not considered of significance in human infection, the potential for a role of the glycosylation process in biofilm formation or colonization of surfaces at lower temperatures requires further investigation. In addition, binding via flagellar glycans to surface receptors of free-living protozoal hosts may be an important mechanism for entry and survival of a number of important bacterial pathogens such as L. monocytogenes (Inglis et al., 2003; Ly \& Muller, 1990).

Clostridium spp. While little is known regarding the specifics of flagellar structures and organization amongst Clostridium spp., motility is a recognized feature of a number of members, including the important human pathogens Clostridium botulinum and Clostridium difficile, as well as the commercially relevant Clostridium tyrobutyricum, which is important in cheese spoilage, and Clostridium acetobutylicum, which is important for solvent production. Preliminary evidence for glycosylation of the flagellin protein from C. tyrobutyricum was presented by Bedouet et al. (1998) and Arnold et al. (1998). Nonreductive $\beta$-elimination of the flagellin protein revealed a mass shift and loss of binding of a monoclonal antibody, indicative of $O$-linked glycosylation which is part of the antigenic epitope recognized by the antibody. In addition, some alkali-resistant linked glycan was observed, suggestive 
of a second form of glycosylation. Analysis of C. acetobutylicum flagellin indicated that the protein is modified with an additional $12 \mathrm{kDa}$ of modification which is sensitive to periodate oxidation. This glycan modification was insensitive to $\mathrm{N}$-glycosidase $\mathrm{F}$, endoglycosidase $\mathrm{H}$ and $O$-glycosidase yet was sensitive to neuraminidase treatment, indicating that a 'sialic acid like' sugar is a glycan component (Lyristis et al., 2000). Bioinformatics analysis of the recently completed genomes of $C$. botulinum and C. difficile has identified a number of glycan biosynthetic genes within the flagellar biosynthetic loci, indicating that glycosylation may be an integral part of the respective motility systems found in these organisms (S. M. Logan, unpublished data).

Butyrivibrio fibrisolvens. The flagella of this Gram-positive rumen anaerobe have been described as subpolar and complex in nature, with two flagellin structural genes identified and sequenced. In addition, the flagellin proteins were shown to be glycosylated using a DIG glycan detection kit (Kalmokoff et al., 2000). The structural basis of this glycosylation is currently unknown.

The genetic and structural characterization of flagellar glycosylation systems of Gram-positive bacteria is clearly still in its infancy although the examples described here indicate that, as with Gram-negative bacteria, the glycans are attached via $O$-linkage. The role of this process in flagellar assembly and its contribution to biological interactions for respective organisms remain to be determined.

\section{$\boldsymbol{O}$-Glycosidic vs $\mathbf{N}$-glycosidic linkage of flagellar proteins}

It is clear from the body of work presented in this review that the glycosylation of bacterial and archaeal flagellins appears to occur via two unique processes which are the consequence of the distinct mechanisms of assembly for the respective flagellar structures. The incorporation of archaeal flagellins into the growing filament occurs following cleavage of the preflagellin signal sequence in a similar fashion to that described for type IV pili (for a review see Craig et al., 2004). Glycosylation of the mature flagellin protein likely occurs in typical $\mathrm{N}$-linked fashion at the periplasmic face of the inner membrane, where the oligosaccharyltransferase (PglB) transfers the assembled glycan from a lipid-linked carrier to the protein backbone (for a review see Szymanski \& Wren, 2005). However, the mechanistic basis for specific targeting of a limited number of proteins to the glycosylation machinery remains to be determined; many proteins are secreted from the cell and would be associated with the periplasmic face of the cell membrane during this process.

In contrast, the $O$-glycosylation of bacterial flagellin appears to be a far more compartmentalized/sequestered event. To date, no reports of other cellular bacterial proteins carrying the same $O$-glycan have been reported in any of the aforementioned bacterial species (with the exception of the flagellar hook protein of $H$. pylori; personal observation).
The detailed mechanistic studies of flagellar assembly have revealed that newly synthesized flagellin protein is prevented from premature monomer interaction in the cytoplasm as a consequence of interaction with FliS, the cytosolic chaperone protein which binds to a C-terminal 40 amino acid region (Evdokimov et al., 2003; Ozin et al., 2003). Targeting of the flagellin monomers to the export apparatus is mediated by specific $\mathrm{N}$-terminus sequence recognition and the protein is secreted through the type III secretion system pore/basal body structure along the hollow core of the growing filament to the tip, where it is then incorporated (Macnab, 2003). It is difficult to conceive that glycosylation of the protein would take place at the tip of the filament and at no time are these flagellins exposed to the periplasmic face of the inner membrane, so our current working hypothesis is that $\mathrm{O}$-glycosylation takes place either in the sequestered basal body environment (either external to the cell membrane or as the protein monomer passes through), or at the cytoplasmic face of the inner membrane in the close vicinity of the basal body. This would permit the assembly of complexes required for the process of glycosylation, in particular for the type of complex glycans composed of multiple monosaccharides as exemplified by $P$. aeruginosa PAK flagellin. A hypothetical and somewhat speculative model comparing the archaeal and bacterial processes is presented in Fig. 1. For the bacterial flagellin glycoproteins characterized to date it is apparent that the sites of $O$ glycosylation are likely localized to surface-exposed domains of the flagellin protein assembled in the flagellar filament (Samatey et al., 2000). Whether this is a consequence of the conserved functional requirements of specific sequences at $\mathrm{N}$ - and C-termini, which are essential for critical monomermonomer interactions within the filament, or the state of the protein (either unfolded or partially folded) when it comes into contact with the specific glycosyltransfereases remains to be established, although a recent study on pilin glycosylation in Pseudomonas indicated that the pilin is folded prior to glycosylation (Horzempa et al., 2005). It should be emphasized that in the current model presented in Fig. 1, while we suggest that the chaperone-flagellin interaction may prevent glycosylation of C-terminal regions, it is currently unclear what state the flagellin protein is in during transit through the central channel. Additionally, our current knowledge of $O$-glycosylation has failed to identify any consensus sequence. It remains to be established what contribution the specific folded state of the protein and local environment of serine/threonine residues makes, in addition to distinct substrate specificities of each respective glycosyltransferase enzyme, to the glycosylation process.

\section{Glycoengineering}

Along with the recent exploitation of the novel bacterial $\mathrm{N}$-linked general protein glycosylation system of Campylobacter for the production of glycoproteins of relevance in antimicrobial therapy (Feldman et al., 2005), the flagellar $\mathrm{N}$-linked systems of Archaea and the bacterial flagellar $O$-linked process described here also have considerable 


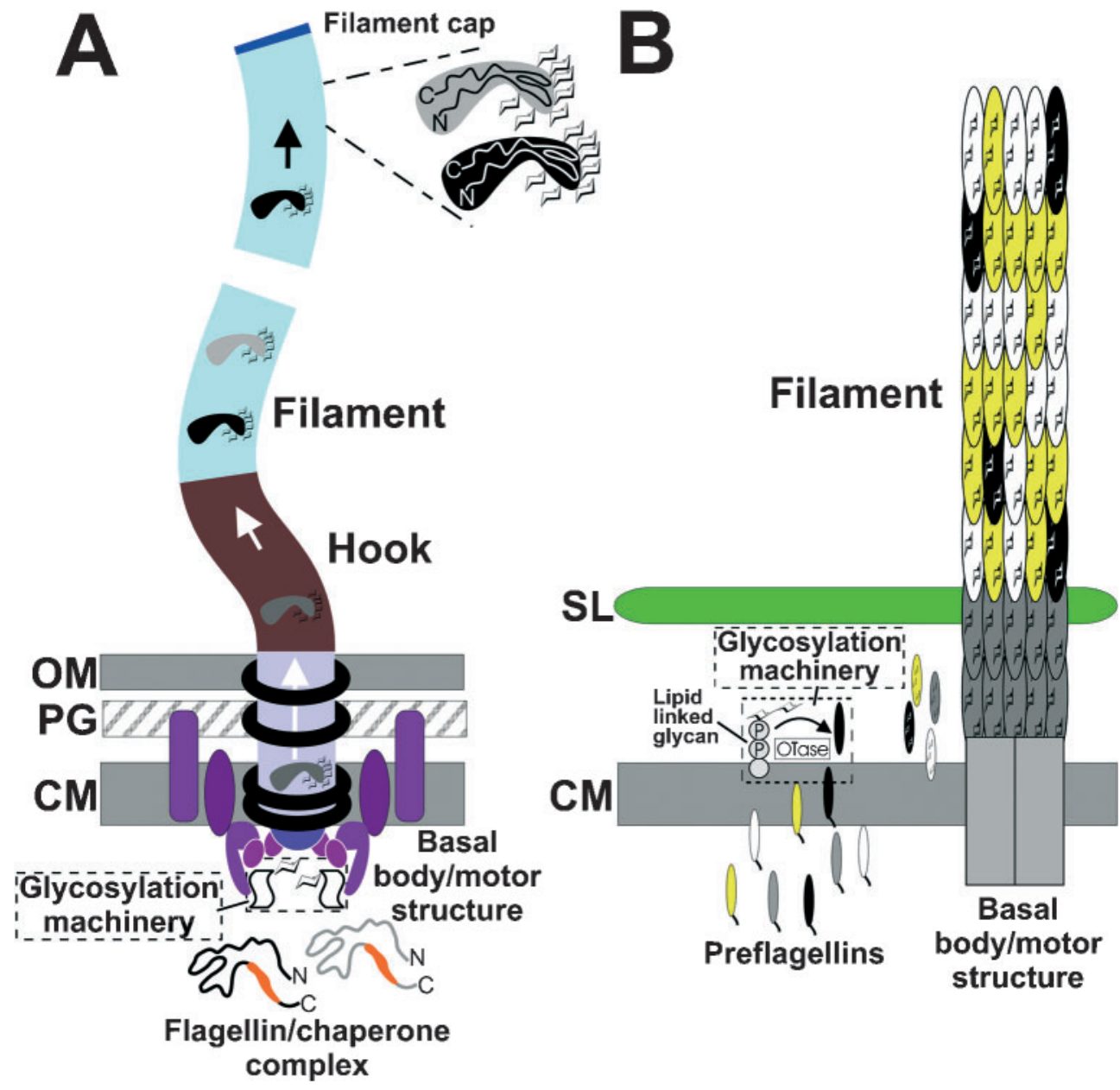

Fig. 1. Schematic representation of a speculative model for $O$ - and $N$-linked flagellar glycosylation. (A) In Bacteria, $O$-linked flagellin glycosylation is proposed to occur at the cytoplasmic face of the inner membrane in the vicinity of the basal body/type III secretion complex. Nucleotide-activated sugars are added to serine and threonine residues which are surface exposed in the flagellin protein-chaperone complex by specific glycosyltransferases of the glycosylation machinery. These glycosylated flagellin monomers are then secreted through the basal body and hook regions to the filament tip, where they are incorporated into the growing filament. Flagellin monomers in the cytosol interact with a flagellin-specific chaperone protein (orange) to prevent premature polymerization (adapted from MacNab, 2003). Grey and black subunits represent different flagellin structural proteins of complex flagellar structures. In the assembled filament, the $\mathrm{N}$ - and C-terminal regions which constitute the D0 and D1 domains are internal and not exposed at the surface. OM, outer membrane; PG, peptidoglycan layer; CM, cytoplasmic membrane. (B) In Archaea, $N$-linked glycosylation is proposed to occur at the outer face of the cell membrane. The assembly of the glycan occurs on a lipid-linked carrier in the cytoplasm and is then 'flipped' across the inner membrane by an $\mathrm{ABC}$ transporter in a similar fashion to $\mathrm{N}$-linked glycosylation of Campylobacter. The flagellin monomer, which is synthesized as a preflagellin with a short positively charged leader peptide, is glycosylated by an oligosaccharyltransferase enzyme (OTase, an orthologue of PglB from C. jejuni) at the outer face of the cell membrane prior to incorporation into the flagellar filament. In contrast to the bacterial filament, the archaeal filament lacks a central channel and it is believed that newly synthesized monomers are incorporated at the base at the outer face of the membrane. PG, peptidoglycan layer; SL, S-layer. (Adapted from Thomas et al., 2001; reprinted with permission from the Annual Review of Microbiology, volume 57 (C) 2003 by Annual Reviews www.annualreviews.org/).

potential. Both novel structures and novel biosynthetic enzymes which may have application in glycoengineering have already been revealed. In the study of $M$. voltae flagellar glycosylation, it was demonstrated that $\beta$-GlcNAc was the linkage sugar to Asn for each $N$-linked sequon. This linkage is commonly found in many eukaryotic systems for the attachment of the complex polymannose oligosaccharides which have considerable biological significance and so points to the potential of utilizing recombinant enzymes from these organisms for glycoengineering purposes. It is 
noteworthy that BLAST analysis of current bacterial genome databases reveals a large number of environmental isolates which contain homologues of a number of flagellar glycosylation genes or genes with homology to glycan biosynthetic genes. These organisms may provide a diverse source of novel structures and enzymes with unique properties for glycoengineering purposes. The identification of $\beta$-O-linked GlcNAc on L. monocytogenes flagellin points to the potential of this system for exploitation in recombinant biosynthesis of relevant eukaryotic nuclear and cytosolic O-linked glycopeptides carrying this important modification.

The identification of the ald-2-ulosonic acid, Pse and related derivatives on the flagellin of a number of organisms is also of relevance for glycoengineering applications. Deoxysugars, which are formed from common monosaccharides in plants, fungi and bacteria, are now recognized as an important unique class of bioactive molecules with great potential, most notably in the glycosylation of antibiotics and in the development of novel anticancer drugs (Salas et al., 2005; Trefzer et al., 1999). The recent demonstration of the exquisite specificity of dehydratase/aminotransferase enzyme pairs from the Pse and related bacillosamine pathways (Schoenhofen et al., 2006) adds to the biosynthetic toolbox for the synthesis of these unique bioactive molecules.

These flagellar systems also offer the potential to express in high quantities a recombinant glycopeptide within an immunodominant bacterial protein for presentation to the immune system. It has been shown that the central region of the flagellin monomer can be utilized for recombinant expression of novel peptide antigens (Cattozzo et al., 1997; Newton et al., 1995). With the identification and characterization of flagellar-specific $O$-linked glycosylation systems, the potential now exists to expand such a process to a glycopeptide expression system.

\section{Novel bacterial therapeutic targets}

A number of the organisms described in this review which produce glycosylated flagellins are significant human pathogens. There is clear evidence that the glycosylation process is either essential for flagellar assembly and subsequent colonization (Schirm et al., 2003; Thibault et al., 2001) or plays a role in virulence of these pathogens (Arora et al., 2005; Rabaan et al., 2001). As a consequence, small-molecule inhibitors of the respective biosynthetic pathway enzymes or the glycosyltransferases responsible for the addition of glycan to the protein offer potential as novel therapeutic agents in much the same way as has recently been suggested for type III secretion systems (Kauppi et al., 2003; Nordfelth et al., 2005). The detailed functional characterization for the enzymes responsible for the initial steps in the Pse biosynthetic pathway may provide such targets for the design of small-molecule inhibitors which will prevent flagellar assembly and consequently prevent the colonization of the gastrointestinal tract by C. jejuni and H. pylori (Chou et al., 2005; Schoenhofen et al., 2006).

\section{Closing remarks}

Flagellar glycosylation can no longer be considered a rare anomaly found in only a few bacterial species with little biological relevance. Not only has the process been shown to be integral to the assembly of complex, polar flagella; the diversity of glycan structures found on organisms from unique environments points to novel biological roles which have yet to be revealed. It has been clearly demonstrated that the flagellin secreted by the flagellin-specific type III pathway can be glycosylated, and so it is tempting to speculate that glycosylation of other proteins secreted either by this pathway or other type III secretion systems may also occur. As yet no evidence for this has been presented although the biological advantages of glycosylation for secreted proteins may be substantial: for example targeting to receptors, increased stability, resistance to proteolysis, immune regulation. If indeed nature has not taken advantage of this process, the potential of such a system from a glycoengineering perspective remains to be realized.

\section{Acknowledgements}

I would like to thank my colleagues John Kelly and Pierre Thibault for their valuable contributions in mass spectroscopy analysis. In addition, I thank Ian C. Schoenhofen for his critical reading of this review. I am grateful to T. Devesceri for his help with figure preparation.

\section{References}

Aldridge, P. \& Hughes, K. T. (2002). Regulation of flagellar assembly. Curr Opin Microbiol 5, 160-165.

Alm, R. A., Guerry, P., Power, M. E. \& Trust, T. J. (1992). Variation in antigenicity and molecular weight of Campylobacter coli VC167 flagellin in different genetic backgrounds. J Bacteriol 174, 4230-4238.

Alm, R. A., Ling, L. S., Moir, D. T. \& 20 other authors (1999). Genomic-sequence comparison of two unrelated isolates of the human gastric pathogen Helicobacter pylori. Nature 397, 176-180.

Andrutis, K. A., Fox, J. G., Schauer, D. B., Marini, R. P., Li, X., Yan, L., Josenhans, C. \& Suerbaum, S. (1997). Infection of the ferret stomach by isogenic flagellar mutant strains of Helicobacter mustelae. Infect Immun 65, 1962-1966.

Arnold, F., Bedouet, L., Batina, P., Robreau, G., Talbot, F., Lecher, P. \& Malcoste, R. (1998). Biochemical and immunological analyses of the flagellin of Clostridium tyrobutyricum ATCC 25755. Microbiol Immunol 42, 23-31.

Arora, S. K., Wolfgang, M. C., Lory, S. \& Ramphal, R. (2004). Sequence polymorphism in the glycosylation island and flagellins of Pseudomonas aeruginosa. J Bacteriol 186, 2115-2122.

Arora, S. K., Neely, A. N., Blair, B., Lory, S. \& Ramphal, R. (2005). Role of motility and flagellin glycosylation in the pathogenesis of Pseudomonas aeruginosa burn wound infections. Infect Immun 73, 4395-4398.

Bardy, S. L., Ng, S. Y. \& Jarrell, K. F. (2003). Prokaryotic motility structures. Microbiology 149, 295-304.

Bardy, S. L., Ng, S. Y. \& Jarrell, K. F. (2004). Recent advances in the structure and assembly of the archaeal flagellum. J Mol Microbiol Biotechnol 7, 41-51. 
Bedouet, L., Arnold, F., Robreau, G., Batina, P., Talbot, F. \& Binet, A. (1998). Evidence for an heterogeneous glycosylation of the Clostridium tyrobutyricum ATCC 25755 flagellin. Microbios 94, 183-192.

Black, R. E., Levine, M. M., Clements, M. L., Hughes, T. P. \& Blaser, M. J. (1988). Experimental Campylobacter jejuni infection in humans. J Infect Dis 157, 472-479.

Bodenmiller, D., Toh, E. \& Brun, Y. V. (2004). Development of surface adhesion in Caulobacter crescentus. J Bacteriol 186, 1438-1447.

Brahamsha, B. \& Greenberg, E. P. (1988). Biochemical and cytological analysis of the complex periplasmic flagella from Spirochaeta aurantia. J Bacteriol 170, 4023-4032.

Carrillo, C. D., Taboada, E., Nash, J. H. \& 15 other authors (2004). Genome-wide expression analyses of Campylobacter jejuni NCTC11168 reveals coordinate regulation of motility and virulence by flhA. J Biol Chem 279, 20327-20338.

Castric, P., Cassels, F. J. \& Carlson, R. W. (2001). Structural characterization of the Pseudomonas aeruginosa 1244 pilin glycan. $J$ Biol Chem 276, 26479-26485.

Cattozzo, E. M., Stocker, B. A., Radaelli, A., De Giuli, M. C. \& Tognon, M. (1997). Expression and immunogenicity of V3 loop epitopes of HIV-1, isolates SC and WMJ2, inserted in Salmonella flagellin. J Biotechnol 56, 191-203.

Champion, O. L., Gaunt, M. W., Gundogdu, O., Elmi, A., Witney, A. A., Hinds, J., Dorrell, N. \& Wren, B. W. (2005). Comparative phylogenomics of the food-borne pathogen Campylobacter jejuni reveals genetic markers predictive of infection source. Proc Natl Acad Sci U S A 102, 16043-16048.

Charon, N. W. \& Goldstein, S. F. (2002). Genetics of motility and chemotaxis of a fascinating group of bacteria: the spirochetes. Annu Rev Genet 36, 47-73.

Chou, W. K., Dick, S., Wakarchuk, W. W. \& Tanner, M. E. (2005). Identification and characterization of NeuB3 from Campylobacter jejuni as a pseudaminic acid synthase. J Biol Chem 43, 35922-35928.

Craig, L., Pique, M. E. \& Tainer, J. A. (2004). Type IV pilus structure and bacterial pathogenicity. Nat Rev Microbiol 2, 363-378.

Creuzenet, C. (2004). Characterization of CJ1293, a new UDPGlcNAc C6 dehydratase from Campylobacter jejuni. FEBS Lett 559, 136-140.

Creuzenet, C., Schur, M. J., Li, J., Wakarchuk, W. W. \& Lam, J. S. (2000). FlaA1, a new bifunctional UDP-GlcNAc C6 Dehydratase/C4 reductase from Helicobacter pylori. J Biol Chem 275, 34873-34880.

Croes, C. L., Moens, S., Van Bastelaere, E., Vanderleyden, J. \& Michiels, K. W. (2004). The polar flagellum mediates Azospirillum brasilense adsorption to wheat roots. J Gen Microbiol 139, 960-967.

Deakin, W. J., Parker, V. E., Wright, E. L., Ashcroft, K. J., Loake, G. J. \& Shaw, C. H. (1999). Agrobacterium tumefaciens possesses a fourth flagellin gene located in a large gene cluster concerned with flagellar structure, assembly and motility. Microbiology 145, 1397-1407.

Dell, A. \& Morris, H. R. (2001). Glycoprotein structure determination by mass spectrometry. Science 291, 2351-2356.

Doig, P. \& Trust, T. J. (1994). Identification of surface-exposed outer membrane antigens of Helicobacter pylori. Infect Immun 62, 4526-4533.

Doig, P., Kinsella, N., Guerry, P. \& Trust, T. J. (1996). Characterization of a post-translational modification of Campylobacter flagellin: identification of a sero-specific glycosyl moiety. Mol Microbiol 19, 379-387.

Dons, L., Rasmussen, O. F. \& Olsen, J. E. (1992). Cloning and characterization of a gene encoding flagellin of Listeria monocytogenes. Mol Microbiol 6, 2919-2929.

Driks, A., Bryan, R., Shapiro, L. \& DeRosier, D. J. (1989). The organization of the Caulobacter crescentus flagellar filament. $\mathrm{J} \mathrm{Mol}$ Biol 206, 627-636.
Eaton, K. A., Suerbaum, S., Josenhans, C. \& Krakowka, S. (1996) Colonization of gnotobiotic piglets by Helicobacter pylori deficient in two flagellin genes. Infect Immun 64, 2445-2448.

Engelhardt, H., Schuster, S. C. \& Baeuerlein, E. (1993). An archimedian spiral: the basal disk of the Wolinella flagellar motor. Science 262, 1046-1048.

Evdokimov, A. G., Phan, J., Tropea, J. E., Routzahn, K. M., Peters, H. K., Pokross, M. \& Waugh, D. S. (2003). Similar modes of polypeptide recognition by export chaperones in flagellar biosynthesis and type III secretion. Nat Struct Biol 10, 789-793.

Feldman, M. F., Wacker, M., Hernandez, M. \& 7 other authors (2005). Engineering $\mathrm{N}$-linked protein glycosylation with diverse $\mathrm{O}$ antigen lipopolysaccharide structures in Escherichia coli. Proc Natl Acad Sci U S A 102, 3016-3021.

Ferris, F. G., Beveridge, T. J., Marceau-Day, M. L. \& Larson, A. D. (1984). Structure and cell envelope associations of flagellar basal complexes of Vibrio cholerae and Campylobacter fetus. Can J Microbiol 30, 322-333.

Fox, J. G. (2002). The non-H. pylori helicobacters: their expanding role in gastrointestinal and systemic diseases. Gut 50, 273-283.

Fuerst, J. A. (1980). Bacterial sheathed flagella and the rotary motor model for the mechanism of bacterial motility. J Theor Biol 84, 761-774.

Gavin, R., Rabaan, A. A., Merino, S., Tomas, J. M., Gryllos, I. \& Shaw, J. G. (2002). Lateral flagella of Aeromonas species are essential for epithelial cell adherence and biofilm formation. Mol Microbiol 43, 383-397.

Ge, Y., Li, C., Corum, L., Slaughter, C. A. \& Charon, N. W. (1998), Structure and expression of the FlaA periplasmic flagellar protein of Borrelia burgdorferi. J Bacteriol 180, 2418-2425.

Geis, G., Suerbaum, S., Forsthoff, B., Leying, H. \& Opferkuch, W. (1993). Ultrastructure and biochemical studies of the flagellar sheath of Helicobacter pylori. J Med Microbiol 38, 371-377.

Gober, J. W. \& Marques, M. V. (1995). Regulation of cellular differentiation in Caulobacter crescentus. Microbiol Rev 59, 31-47.

Goon, S., Kelly, J. F., Logan, S. M., Ewing, C. P. \& Guerry, P. (2003). Pseudaminic acid, the major modification on Campylobacter flagellin, is synthesized via the Cj1293 gene. Mol Microbiol 50, 659-671.

Gryllos, I., Shaw, J. G., Gavin, R., Merino, S. \& Tomas, J. M. (2001). Role of $\mathrm{flm}$ locus in mesophilic Aeromonas species adherence. Infect Immun 69, 65-74.

Guerry, P., Doig, P., Alm, R. A., Burr, D. H., Kinsella, N. \& Trust, T. J. (1996). Identification and characterization of genes required for post-translational modification of Campylobacter coli VC167 flagellin. Mol Microbiol 19, 369-378.

Horzempa, J., Comer, J. E., Davis, S. A. \& Castric, P. (2005) Glycosylation substrate specificity of Pseudomonas aeruginosa 1244 Pilin. J Biol Chem 281, 1128-1136.

Hranitzky, K. W., Mulholland, A., Larson, A. D., Eubanks, E. R. \& Hart, L. T. (1980). Characterization of a flagellar sheath protein of Vibrio cholerae. Infect Immun 27, 597-603.

Inglis, T. J., Robertson, T., Woods, D. E., Dutton, N. \& Chang, B. J. (2003). Flagellum-mediated adhesion by Burkholderia pseudomallei precedes invasion of Acanthamoeba astronyxis. Infect Immun 71, 2280-2282.

Johnson, R. C., Ferber, D. M. \& Ely, B. (1983). Synthesis and assembly of flagellar components by Caulobacter crescentus motility mutants. J Bacteriol 154, 1137-1144.

Josenhans, C., Ferrero, R. L., Labigne, A. \& Suerbaum, S. (1999), Cloning and allelic exchange mutagenesis of two flagellin genes of Helicobacter felis. Mol Microbiol 33, 350-362. 
Josenhans, C., Vossebein, L., Friedrich, S. \& Suerbaum, S. (2002). The neuA/flmD gene cluster of Helicobacter pylori is involved in flagellar biosynthesis and flagellin glycosylation. FEMS Microbiol Lett 210, 165-172.

Kalmokoff, M. L., Allard, S., Austin, J. W., Whitford, M. F., Hefford, M. A. \& Teather, R. M. (2000). Biochemical and genetic characterisation of the flagellar filaments from the ruman anaerobe Butyrivibrio fibrisolvens OR77. Anaerobe 6, 93-109.

Karlyshev, A. V., Linton, D., Gregson, N. A. \& Wren, B. W. (2002). A novel paralogous gene family involved in phase-variable flagellamediated motility in Campylobacter jejuni. Microbiology 148, 473-480.

Kauppi, A. M., Nordfelth, R., Uvell, H., Wolf-Watz, H. \& Elofsson, M. (2003). Targeting bacterial virulence: inhibitors of type III secretion in Yersinia. Chem Biol 10, 241-249.

Kirov, S. M., Tassell, B. C., Semmler, A. B., O’Donovan, L. A., Rabaan, A. A. \& Shaw, J. G. (2002). Lateral flagella and swarming motility in Aeromonas species. J Bacteriol 184, 547-555.

Krupski, G., Gotz, R., Ober, K., Pleier, E. \& Schmitt, R. (1985). Structure of complex flagellar filaments in Rhizobium meliloti. J Bacteriol 162, 361-366.

Leclerc, G., Wang, S. P. \& Ely, B. (1998). A new class of Caulobacter crescentus flagellar genes. J Bacteriol 180, 5010-5019.

Li, Z., Dumas, F., Dubreuil, D. \& Jacques, M. (1993). A speciesspecific periplasmic flagellar protein of Serpulina (Treponema) hyodysenteriae. J Bacteriol 175, 8000-8007.

Li, C., Motaleb, A., Sal, M., Goldstein, S. F. \& Charon, N. W. (2000). Spirochete periplasmic flagella and motility. $J$ Mol Microbiol Biotechnol 2, 345-354.

Linton, D., Karlyshev, A. V., Hitchen, P. G., Morris, H. R., Dell, A., Gregson, N. A. \& Wren, B. W. (2000). Multiple $N$-acetylneuraminic acid synthetase $(n e u B)$ genes in Campylobacter jejuni: identification and characterization of the gene involved in sialylation of lipooligosaccharide. Mol Microbiol 35, 1120-1134.

Logan, S. M., Trust, T. J. \& Guerry, P. (1989). Evidence for posttranslational modification and gene duplication of Campylobacter flagellin. J Bacteriol 171, 3031-3038.

Logan, S. M., Kelly, J. F., Thibault, P., Ewing, C. P. \& Guerry, P. (2002). Structural heterogeneity of carbohydrate modifications affects serospecificity of Campylobacter flagellins. Mol Microbiol 46, 587-597.

Ly, T. M. \& Muller, H. E. (1990). Ingested Listeria monocytogenes survive and multiply in protozoa. $J$ Med Microbiol 33, 51-54.

Lyristis, M., Boynton, Z. L., Petersen, D., Kan, Z., Bennett, G. N. \& Rudolph, F. B. (2000). Cloning, sequencing and characterisation of the gene encoding flagellin, flaC and the posttranslational modification of flagellin, FlaC from Clostridium acetobutylicum ATCC824. Anaerobe 6, 69-79.

Macnab, R. M. (2003). How bacteria assemble flagella. Annu Rev Microbiol 57, 77-100.

McCarter, L. L. (2001). Polar flagellar motility of the Vibrionaceae. Microbiol Mol Biol Rev 65, 445-462.

McCarter, L. L. (2004). Dual flagellar systems enable motility under different circumstances. J Mol Microbiol Biotechnol 7, 18-29.

Merkx-Jacques, A., Obhi, R. K., Bethune, G. \& Creuzenet, C. (2004). The Helicobacter pylori flaA1 and $w b p B$ genes control lipopolysaccharide and flagellum synthesis and function. J Bacteriol 186, 2253-2265.

Moens, S., Michiels, K. \& Vanderleyden, J. (1995). Glycosylation of the flagellin of the polar flagellum of Azospirillium brazilense Sp7, a Gram-negative nitrogen-fixing bacterium. Microbiology 141, 2651-2657.

Newton, S. M., Joys, T. M., Anderson, S. A., Kennedy, R. C., Hovi, M. E. \& Stocker, B. A. (1995). Expression and immunogenicity of an 18-residue epitope of HIV1 gp41 inserted in the flagellar protein of a Salmonella live vaccine. Res Microbiol 146, 203-216.

Nordfelth, R., Kauppi, A. M., Norberg, H. A., Wolf-Watz, H. \& Elofsson, M. (2005). Small-molecule inhibitors specifically targeting type III secretion. Infect Immun 73, 3104-3114.

Obhi, R. K. \& Creuzenet, C. (2005). Biochemical characterization of the Campylobacter jejuni Cj1294, a novel UDP-4-keto-6-deoxy-GlcNAc aminotransferase that generates UDP-4-amino-4,6-dideoxy-GalNAc. J Biol Chem 280, 20902-20908.

Ozin, A. J., Claret, L., Auvray, F. \& Hughes, C. (2003). The FliS chaperone selectively binds the disordered flagellin C-terminal D0 domain central to polymerisation. FEMS Microbiol Lett 219, 219-224.

Pallen, M. J., Penn, C. W. \& Chaudhuri, R. R. (2005). Bacterial flagellar diversity in the post-genomic era. Trends Microbiol 13, 143-149. Parkhill, J., Wren, B. W., Mungall, K. \& 18 other authors (2000). The genome sequence of the food-borne pathogen Campylobacter jejuni reveals hypervariable sequences. Nature 403, 665-668.

Peel, M., Donachie, W. \& Shaw, A. (1988). Physical and antigenic heterogeneity in the flagellins of Listeria monocytogenes and $L$. ivanovii. J Gen Microbiol 134, 2593-2598.

Power, P. \& Jennings, M. P. (2003). The genetics of glycosylation in Gram negative bacteria. FEMS Microbiol Lett 218, 211-222.

Rabaan, A. A., Gryllos, I., Tomas, J. M. \& Shaw, J. G. (2001). Motility and the polar flagellum are required for Aeromonas caviae adherence to HEp-2 cells. Infect Immun 69, 4257-4267.

Rademaker, G. J. \& Thomas-Oates, J. (1996). Analysis of glycoproteins and glycopeptides using fast-atom bombardment. Methods Mol Biol 61, 231-241.

Salas, A. P., Zhu, L., Sanchez, C., Brana, A. F., Rohr, J., Mendez, C. \& Salas, J. A. (2005). Deciphering the late steps in the biosynthesis of the anti-tumour indolocarbazole staurosporine: sugar donor substrate flexibility of the StaG glycosyltransferase. Mol Microbiol 58, 17-27.

Samatey, F. A., Imada, K., Vonderviszt, F., Shirakihara, Y. \& Namba, K. (2000). Crystallization of the F41 fragment of flagellin and data collection from extremely thin crystals. J Struct Biol 132, 106-111.

Schaffer, C. \& Messner, P. (2004). Surface-layer glycoproteins: an example for the diversity of bacterial glycosylation with promising impacts on nanobiotechnology. Glycobiology 14, 31R-42R.

Schirm, M., Soo, E. C., Aubry, A. J., Austin, J., Thibault, P. \& Logan, S. M. (2003). Structural, genetic and functional characterization of the flagellin glycosylation process in Helicobacter pylori. Mol Microbiol 48, 1579-1592.

Schirm, M., Arora, S. K., Verma, A., Vinogradov, E., Thibault, P., Ramphal, R. \& Logan, S. M. (2004a). Structural and genetic characterization of glycosylation of type a flagellin in Pseudomonas aeruginosa. J Bacteriol 186, 2523-2531.

Schirm, M., Kalmokoff, M., Aubry, A., Thibault, P., Sandoz, M. \& Logan, S. M. (2004b). Flagellin from Listeria monocytogenes is glycosylated with beta-O-linked $\mathrm{N}$-acetylglucosamine. J Bacteriol 186, 6721-6727.

Schirm, M., Schoenhofen, I. C., Logan, S. M., Waldron, K. C. \& Thibault, P. (2005). Identification of unusual bacterial glycosylation by tandem mass spectrometry analyses of intact proteins. Anal Chem 77, 7774-7782.

Schoenhofen, I. C., McNally, D. J., Vinogradov, E., Whitfield, D., Young, M., Dick, S., Wakarchuk, W. W., Brisson, J.-R. \& Logan, S. M. (2006). Functional characterisation of dehydratase/aminotransferase pairs from Helicobacter and Campylobacter: enzymes distinguishing the pseudaminic acid and bacillosamine biosynthetic pathways. J Biol Chem 281, 723-732.

Schuster, S. C. \& Khan, S. (1994). The bacterial flagellar motor. Annu Rev Biophys Biomol Struct 23, 509-539. 
Soo, E. C., Aubry, A. J., Logan, S. M., Guerry, P., Kelly, J. F., Young, N. M. \& Thibault, P. (2004). Selective detection and identification of sugar nucleotides by CE-electrospray-MS and its application to bacterial metabolomics. Anal Chem 76, 619-626.

Szymanski, C. M. \& Wren, B. W. (2005). Protein glycosylation in bacterial mucosal pathogens. Nat Rev Microbiol 3, 225-237.

Szymanski, C. M., Logan, S. M., Linton, D. \& Wren, B. W. (2003). Campylobacter - a tale of two protein glycosylation systems. Trends Microbiol 11, 233-238.

Taguchi, F., Shimizu, R., Ikeda, Y., Inagaki, Y., Toyoda, K., Shiraishi, T. \& Ichinose, Y. (2003). Post-translational modification of flagellin determines the specific induction of HR. Plant Physiol Biochem 44, 342-349.

Takeuchi, K., Taguchi, F., Inagaki, Y., Toyoda, K., Shiraishi, T. \& Ichinose, Y. (2003). Flagellin glycosylation island in Pseudomonas syringae pv glycinea and its role in host specificity. J Bacteriol 185, 6658-6665.

Thibault, P., Logan, S. M., Kelly, J. F., Brisson, J. R., Ewing, C. P., Trust, T. J. \& Guerry, P. (2001). Identification of the carbohydrate moieties and glycosylation motifs in Campylobacter jejuni flagellin. $J$ Biol Chem 276, 34862-34870.

Thomas, N. A., Bardy, S. L. \& Jarrell, K. F. (2001). The archaeal flagellum: a different kind of prokaryotic motility structure. FEMS Microbiol Rev 25, 147-174.

Thomashow, L. S. \& Rittenberg, S. C. (1985a). Isolation and composition of sheathed flagella from Bdellovibrio bacteriovorus 109J. J Bacteriol 163, 1047-1054.
Thomashow, L. S. \& Rittenberg, S. C. (1985b). Waveform analysis and structure of flagella and basal complexes from Bdellovibrio bacteriovorus 109J. J Bacteriol 163, 1038-1046.

Thornley, J. P., Shaw, J. G., Gryllos, I. A. \& Eley, E. (1997). Virulence properties of clinically significant Aeromonas species: evidence for pathogenicity. Rev Med Microbiol 8, 61-72.

Tomb, J. F., White, O., Kerlavage, A. R. \& 22 other authors (1997). The complete genome sequence of the gastric pathogen Helicobacter pylori. Nature 388, 539-547.

Totten, P. A. \& Lory, S. (1990). Characterization of the type a flagellin gene from Pseudomonas aeruginosa PAK. J Bacteriol 172, 7188-7199.

Trefzer, A., Salas, J. A. \& Bechthold, A. (1999). Genes and enzymes involved in deoxysugar biosynthesis in bacteria. Nat Prod Rep 16, 283-299.

Voisin, S., Houliston, R. S., Kelly, J., Brisson, J. R., Watson, D., Bardy, S. L., Jarrell, K. F. \& Logan, S. M. (2005). Identification and characterization of the unique $N$-linked glycan common to the flagellins and S-layer glycoprotein of Methanococcus voltae. J Biol Chem 280, 16586-16593.

Wieland, F., Paul, G. \& Sumper, M. (1985). Halobacterial flagellins are sulfated glycoproteins. J Biol Chem 260, 15180-15185.

Wysocki, V. H., Resing, K. A., Zhang, Q. \& Cheng, G. (2005). Mass spectrometry of peptides and proteins. Methods 35, 211-222.

Wyss, C. (1998). Flagellins, but not endoflagellar sheath proteins, of Treponema pallidum and of pathogen-related oral spirochetes are glycosylated. Infect Immun 66, 5751-5754. 